\title{
Factor Analysis-Based Appraisal of the Innovation Performance of China's Hi-Tech Industry
}

\author{
Wang Fusheng ${ }^{1, ~ a}$, Han $\mathrm{He}^{2, \mathrm{~b}}$, Zhao Yanli ${ }^{3, \mathrm{c}}$ \\ ${ }^{1,2}$ Harbin Institute of Technology, Harbin, China \\ ${ }^{3}$ Harbin University of Commerce, Harbin, China \\ aqgjj2015@163.com, b840810710@qq.com, c1904970496@qq.com
}

Keywords: hi-tech industry; innovation performance; factor analysis

\begin{abstract}
It has become an irreversible trend in the global economy for enterprises to shift from the factor-driven development pattern to the innovation-driven development pattern in recent years. The hi-tech industry is characterized by frequent updates and rapid changes and is demanding in respect of independent R\&D and innovation capability, so the hi-tech industry becomes the core subject for practicing the innovation-driven development pattern. Therefore, that how to promote the healthy, rapid and efficient development of the hi-tech industry has gradually attracted a lot of attention and been actively explored in all sectors. To solve the problem, exploration into the innovation performance of the hi-tech industry is of the greatest importance. Hence it is crucial to find a reasonable method of innovation performance appraisal and appraise the performance of China's hi-tech industry objectively by the method.
\end{abstract}

\section{Introduction}

Hi-tech industry is often used in reference to the aggregation of enterprises that, on the basis of high technology, are engaged in one or more high technologies and related R\&D and production of products and technology services. The hi-tech industry made an outstanding contribution to the alleviation of the employment pressure, the maintenance of social stability and the integration into globalization. Despite the rapid growth, segments of the hi-tech industry performed differently and in some areas of China the hi-tech industry hit a bottleneck to growth and dropped. Meanwhile, the hi-tech industries in developed countries remained booming and generally weighed heavily. By contrast, it is obvious that China's hi-tech industry doesn't weigh very much and is poorly structured. It is of great significance to foster, improve and optimize the hi-tech industry and realize optimization and upgrade of the industrial stricture according to China's strategy of building an innovative country that practices sustainable development. We can see that it is an important approach to boosting national economy to promote the development of the hi-tech industry.

\section{Appraisal of Innovation Performance of the Hi-tech Industry}

\subsection{Development of an Indicator System}

It is difficult to appraise an innovation system, an industrial innovation system in particular. The currently mostly used methods are theoretical deduction and case study. The methods facilitate the study of innovation system's internal structure, but they lack operability relatively, so scholars are trying to find a quantitative method of innovation system appraisal in order to appraise the innovation performance.

In view of the availability of data, an in-depth analysis is conducted by drawing lessons from research methods at home and abroad and taking the characteristics of China's hi-tech industry into consideration. According to the analysis, the following indicators are selected for the appraisal of the hi-tech industry's innovation performance: newly increased fixed assets (M1), funds for development 
of new products (M2), output of new products (M3), export delivery (M4), full time equivalent of $R \& D$ personnel (T1), internal expenditure of $R \& D$ funds (T2), patent applications(T3), patents for inventions (T4), researchers (T5), technological transformation expenditure (T6), technological introduction expenditure (T7), digestion \& absorption expenditure (T8), enterprises with R\&D (S1), R\&D personnel (S2), corporate funds (S3), and governmental funds (S4) Thus, we get the system of indicators for appraising the innovation performance of China's hi-tech industry, as shown in Table 1.

Table 1. Performance Appraisal System

\begin{tabular}{|c|c|c|c|}
\hline Primary Indicator & Secondary Indicator & Unit & Serial Number \\
\hline \multirow{4}{*}{ 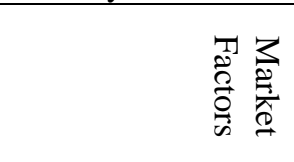 } & Newly increased fixed assets & 10 thousand RMB & M1 \\
\hline & Funds for development of new products & 10 thousand RMB & M2 \\
\hline & Output of new products & 10 thousand RMB & M3 \\
\hline & Export delivery & 10 thousand RMB & M4 \\
\hline \multirow{8}{*}{$\begin{array}{l}\overrightarrow{0} \\
\stackrel{2}{2}\end{array}$} & Full time equivalent of R\&D personnel & Person-year & T1 \\
\hline & Internal expenditure of R\&D funds & 10 thousand RMB & $\mathrm{T} 2$ \\
\hline & Patent applications & & T3 \\
\hline & Patents for inventions & & $\mathrm{T} 4$ \\
\hline & Researchers & & T5 \\
\hline & Technological transformation expenditure & 10 thousand RMB & T6 \\
\hline & Technological introduction expenditure & 10 thousand RMB & T7 \\
\hline & Digestion \& absorption expenditure & 10 thousand RMB & $\mathrm{T} 8$ \\
\hline \multirow{4}{*}{ 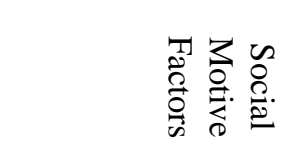 } & Enterprises with R\&D & & S1 \\
\hline & R\&D personnel & & S2 \\
\hline & Corporate funds & 10 thousand RMB & S3 \\
\hline & Governmental funds & 10 thousand RMB & S4 \\
\hline
\end{tabular}

\subsection{Standardization of Indicator System}

With the innovation performance of the hi-tech industry as the objective of the appraisal, 496 data for the 16 indicators regarding China's 31 provincial-level regions in 2016 are selected for analysis. In order to compare the variables and eliminate impact resulting from any observed dimensional discrepancy or order of magnitude, the observed sample data is processed into standard non-dimensional data. The standard data are shown in Appendix A.

\subsection{Test of Indicator System}

First, compute the correlation coefficient matrix to test the indicators. Input the indicators of the sample into SPSS17.0 and get the coefficient matrix of the sample. We see that most correlation coefficients are greater than 0.05 . This implies that factors are linearly independent of each other, i.e. the factors contain no overlapping information. Second, conduct KMO and Bartlett's test. The results are shown in Table 2.

Table 2. KMO and Bartlett's Test

\begin{tabular}{|cc|c|}
\hline \multicolumn{2}{|c|}{ Kaiser-Meyer-Olkin Measure of } & .758 \\
Sampling Adequacy. & \\
Bartlett’s Test of & Approx. & 1237.329 \\
Sphericity & Chi-Square & \\
& Df & 120 \\
& Sig. & .000 \\
\hline
\end{tabular}

The KMO is 0.758 . It indicates that the sampling is adequate. Bartlett's Test of Sphericity shows that the correlation matrix is not an identity matrix. Therefore, it is appropriate to use factor analysis here.

\subsection{Calculation of Eigenvalues and Their Percentage and Accumulative Percentage}

To reduce originally multidimensional variables to a few factors by synthetic dimension reduction 
is at the core of a factor analysis. Factor extraction methods include principal axis factoring, principal component analysis, unweighted least squares, generalized least squares, maximum likelihood, etc. Principal component analysis will be used for factor extraction here. See Table 3 and 4 below for the extraction of the original variables corresponding to the communalities.

Table 3. Communalities

\begin{tabular}{cccccccccc}
\hline & $\mathrm{M} 1$ & $\mathrm{M} 2$ & $\mathrm{M} 3$ & $\mathrm{M} 4$ & $\mathrm{~T} 1$ & $\mathrm{~T} 2$ & $\mathrm{~T} 3$ & $\mathrm{~T} 4$ \\
\hline Initial & 1.000 & 1.000 & 1.000 & 1.000 & 1.000 & 1.000 & 1.000 & 1.000 \\
Extraction & 0.573 & 0.959 & 0.954 & 0.843 & 0.985 & 0.989 & 0.975 & 0.772 \\
\hline & $\mathrm{T} 5$ & $\mathrm{~T} 6$ & $\mathrm{~T} 7$ & $\mathrm{~T} 8$ & $\mathrm{~S} 1$ & $\mathrm{~S} 2$ & $\mathrm{~S} 3$ & $\mathrm{~S} 4$ \\
\hline Initial & 1.000 & 1.000 & 1.000 & 1.000 & 1.000 & 1.000 & 1.000 & 1.000 \\
Extraction & 0.966 & 0.614 & 0.769 & 0.956 & 0.844 & 0.984 & 0.969 & 0.976 \\
\hline
\end{tabular}

Extraction Method: Principal Component Analysis.

Table 4. Total Variance Explained

\begin{tabular}{|c|c|c|c|c|c|c|c|c|c|}
\hline \multirow{2}{*}{ Component } & \multicolumn{3}{|c|}{ Initial Eigenvalues } & \multicolumn{3}{|c|}{$\begin{array}{c}\text { Extraction Sums of Squared } \\
\text { Loadings }\end{array}$} & \multicolumn{3}{|c|}{ Rotation Sums of Squared Loadings } \\
\hline & Total & $\begin{array}{c}\text { \% of } \\
\text { Variance }\end{array}$ & Accumulative \% & Total & $\begin{array}{c}\text { \% of } \\
\text { Variance }\end{array}$ & $\begin{array}{c}\text { Accumulative } \\
\%\end{array}$ & Total & $\begin{array}{c}\text { \% of } \\
\text { Variance }\end{array}$ & $\begin{array}{l}\text { Accumula } \\
\text { tive } \%\end{array}$ \\
\hline 1 & 11.892 & 74.328 & 74.328 & $\begin{array}{c}11.8 \\
92 \\
\end{array}$ & 74.328 & 74.328 & $\begin{array}{c}11.79 \\
2 \\
\end{array}$ & 73.698 & 73.698 \\
\hline 2 & 1.266 & 7.914 & 82.242 & $\begin{array}{c}1.26 \\
6 \\
\end{array}$ & 7.914 & 82.242 & 1.325 & 8.282 & 81.981 \\
\hline 3 & .967 & 6.046 & 88.288 & .967 & 6.046 & 88.288 & 1.009 & 6.307 & 88.288 \\
\hline 4 & .916 & 5.728 & 94.015 & & & & & & \\
\hline 5 & .441 & 2.753 & 96.769 & & & & & & \\
\hline 6 & .211 & 1.318 & 98.086 & & & & & & \\
\hline 7 & .112 & .697 & 98.783 & & & & & & \\
\hline 8 & .087 & .547 & 99.330 & & & & & & \\
\hline 9 & .052 & .325 & 99.655 & & & & & & \\
\hline 10 & .035 & .220 & 99.876 & & & & & & \\
\hline 11 & .009 & .057 & 99.933 & & & & & & \\
\hline 12 & .008 & .052 & 99.985 & & & & & & \\
\hline 13 & .002 & .010 & 99.994 & & & & & & \\
\hline 14 & .001 & .004 & 99.998 & & & & & & \\
\hline 15 & .000 & .002 & 100.000 & & & & & & \\
\hline 16 & $\begin{array}{c}7.413 \mathrm{E} \\
-5 \\
\end{array}$ & .000 & 100.000 & & & & & & \\
\hline
\end{tabular}

Extraction Method: Principal Component Analysis.

In the process of analysis, principal component analysis is used as the factor extraction method and 3 factors are selected. The accumulative percentage of variance explained reaches $88.288 \%$, which indicates that the 3 factors extracted are adequate to interpret the innovation performance of the 31 provincial-level regions. As we can see, Factor 1 accounts for $74.328 \%$ of the variance, the highest, Factor 2 for $7.914 \%$, and Factor 3 for 6.046\%. After the rotation, Factor 1 accounts for $73.698 \%$ of the variance, Factor 2 for $8.282 \%$, and Factor 3 for $6.307 \%$. The 3 factors largely integrate information of the 16 indicators; thus, the 16 indicators are reduced to 3 integrative factor indicators.

\subsection{Calculation of Factor Scores and Composite Scores}

Table 5 shows the loadings of the 3 factors after rotation. As we can see, the loadings of M2, M3, T1, T3, S2 and S3 onto Factor 1 are comparably large, that is, Factor 1 has considerably great effect on these 6 indicators, so we can define Factor 1 as Market Factor. Similarly, the loadings of T2 and T5 onto Factor 2 are relatively large, so we can define Factor 2 as Technology Factor. The loadings of T8 and S5 onto Factor 3 are relatively large, so we can define Factor 3 as Social Motive Factor. In Table 5, we can see that with regard to the 3 factors' interpretation of overall objectives, Factor 1 is the most important. 
Table 5. Component Matrix ${ }^{\mathrm{a}}$

\begin{tabular}{l|ccc}
\hline & \multicolumn{3}{|c}{ Component } \\
\cline { 2 - 4 } M1 & 1 & 2 & 3 \\
\hline M2 & .719 & -.126 & -.201 \\
M3 & .970 & -.126 & .051 \\
M4 & .967 & -.131 & .039 \\
T1 & .880 & -.201 & -.168 \\
T2 & .983 & .099 & -.089 \\
T3 & .937 & .333 & .000 \\
T4 & .953 & -.207 & -.155 \\
T5 & .804 & -.216 & -.282 \\
T6 & .941 & .277 & -.052 \\
T7 & .761 & -.004 & .184 \\
T8 & .833 & -.004 & .276 \\
S1 & .537 & -.085 & .813 \\
S2 & .896 & -.198 & -.032 \\
S3 & .981 & .130 & -.076 \\
S4 & .983 & -.031 & .032 \\
\hline Ext & .385 & .909 & -.046 \\
\hline
\end{tabular}

Extraction Method: Principal Component Analysis. a. 3 components extracted.
Table 6. Factor Score Coefficient Matrix

\begin{tabular}{c|ccc}
\hline & \multicolumn{3}{|c}{ Component } \\
\cline { 2 - 4 } M1 & 1 & 2 & 3 \\
\hline M2 & .060 & -.099 & -.208 \\
M3 & .082 & -.099 & .052 \\
M4 & .081 & -.104 & .040 \\
T1 & .074 & -.159 & -.173 \\
T2 & .083 & .078 & -.092 \\
T3 & .079 & .263 & .000 \\
T4 & .080 & -.164 & -.160 \\
T5 & .068 & -.170 & -.291 \\
T6 & .079 & .219 & -.054 \\
T7 & .064 & -.003 & .190 \\
T8 & .070 & -.003 & .285 \\
S1 & .045 & -.067 & .840 \\
S2 & .075 & -.156 & -.033 \\
S3 & .082 & .102 & -.079 \\
S4 & .083 & -.025 & .033 \\
\hline
\end{tabular}

Extraction Method: Principal Component Analysis.

Table 6 shows the matrix of coefficients used to calculate the scores of the 3 factors from original variables. Thus, we can get the linear combinations of the 3 factors and the 16 indicators. The results of F1 are shown below. The calculation methods for F2 and F3 are the same.

$$
\begin{array}{r}
\mathrm{F} 1=0.060 \mathrm{M} 1+0.082 \mathrm{M} 2+0.081 \mathrm{M} 3+0.074 \mathrm{M} 4+0.083 \mathrm{~T} 1+0.079 \mathrm{~T} 2+0.080 \mathrm{~T} 3+0.068 \mathrm{~T} 4+0.079 \mathrm{~T} 5+0.06 \\
4 \mathrm{~T} 6+0.070 \mathrm{~T} 7+0.045 \mathrm{~T} 8+0.075 \mathrm{~S} 1+0.082 \mathrm{~S} 2+0.083 \mathrm{~S} 3+0.032 \mathrm{~S} 4 ;
\end{array}
$$

Assign raw data of China's 31 provincial-level regions in 2016 to variables in the equations above and we get the factor score of each provincial-level region, as shown in Table 7.

In Table 7 we can see each region's status with regard to each of the 3 factors. Jiangsu is far ahead of other regions in respect of the market of the hi-tech industry, which is largely indebted to its geographical advantage. As China's political and economic center which represents China's highest level in hi-tech areas, Beijing enjoys incomparable technology advantage. As home to a large number of China's institutions of higher learning and scientific research, Shanghai has undoubted capacity for coordination and collaboration, which brings high collaborative effectiveness.

After we figure out the factor scores, we can work out the composite score of each provincial-level region by weighting each factor score according to how much its \% of the variance accounts for the total of the 3 factors' \% of the variance and adding the weighted factor scores up, as illustrated by the following formula:

$$
\mathrm{F}=(73.698 * \mathrm{~F} 1+8.282 * \mathrm{~F} 2+6.307 * \mathrm{~F} 3) /(73.698+8.282+6.307)
$$

According to the composite score formula above, we can get each provincial-level region's total score and rank, as shown in Table 8.

As shown in Table 8, Jiangsu, Guangdong and Shandong take first, second and third places respectively in China's hi-tech industry with their comprehensive advantages in market, technology and social motive. However, large gaps are seen among other regions in respect of their composite scores. As we can find from the analysis above, apart from the northern, eastern and southern coastal economic zones, most regions ranks low on the list of the innovation performance of the high-tech industry. It indicates that China's hi-tech industry is poor at structure and comprehensive strength, 
which is attributed to national policy, economic input and geological conditions. It can be concluded from the analysis of the indicators and factors that in terms of the innovation performance of the hi-tech industry, there are gaps among China's provincial-level regions and that China's hi-tech industry is poor-structured.

Table 7. Factor Score of the Provincial-Level Regions

\begin{tabular}{c|ccc}
\hline & F1 & F2 & F3 \\
\hline Beijing & 0.39992 & 1.11477 & -0.0787 \\
Tianjin & 0.21359 & 0.06691 & 0.24075 \\
Hebei & 0.19693 & 0.05784 & 0.59808 \\
Shanxi & 0.11511 & 0.04931 & 0.28753 \\
Inner Mongolia & 0.06860 & 0.03583 & 0.10533 \\
Liaoning & 0.23697 & 0.18391 & 0.13487 \\
Jilin & 0.07903 & 0.10016 & -0.0153 \\
Heilongjiang & 0.11888 & 0.13607 & 0.11003 \\
Shanghai & 0.47979 & 0.19057 & 0.93864 \\
Jiangsu & 0.92232 & -0.00491 & 0.09060 \\
Zhejiang & 0.53759 & 0.01143 & 0.22425 \\
Anhui & 0.17345 & 0.05470 & 0.04732 \\
Fujian & 0.20254 & 0.01582 & 0.09355 \\
Jiangxi & 0.09982 & 0.02971 & -0.0200 \\
Shandong & 0.59156 & 0.13027 & 0.48292 \\
Henan & 0.22095 & 0.10396 & 0.04962 \\
Hubei & 0.24763 & 0.17321 & 0.10834 \\
Hunan & 0.22509 & 0.03192 & 0.18818 \\
Guangdong & 0.95801 & -0.13916 & -0.2983 \\
Guangxi & 0.07712 & 0.04688 & 0.01651 \\
Hainan & 0.00657 & 0.00594 & 0.00027 \\
Chongqing & 0.12655 & 0.02063 & 0.09557 \\
Sichuan & 0.21427 & 0.32475 & 0.12513 \\
Guizhou & 0.03745 & 0.01794 & -0.1561 \\
Yunnan & 0.05072 & 0.04740 & 0.10541 \\
Tibet & 0.00000 & 0.00000 & 0.00000 \\
Shaanxi & 0.17486 & 0.26817 & -0.1042 \\
Gansu & 0.06513 & 0.02098 & 0.37857 \\
Qinghai & 0.00877 & 0.00638 & 0.02517 \\
Ningxia & 0.01670 & 0.00219 & 0.03530 \\
Xinjiang & 0.02622 & 0.02612 & 0.00088 \\
\hline & & &
\end{tabular}

Table 8.Total Score and Rank of the Provincial-Level Regions

\begin{tabular}{c|cc}
\hline & $\mathrm{F}$ & Rank \\
\hline Beijing & 0.43279 & 6 \\
Tianjin & 0.20177 & 12 \\
Hebei & 0.21254 & 10 \\
Shanxi & 0.12125 & 17 \\
Inner Mongolia & 0.06815 & 24 \\
Liaoning & 0.22470 & 8 \\
Jilin & 0.07427 & 22 \\
Heilongjiang & 0.11986 & 18 \\
Shanghai & 0.48544 & 4 \\
Jiangsu & 0.77592 & 1 \\
Zhejiang & 0.46585 & 5 \\
Anhui & 0.15330 & 16 \\
Fujian & 0.17724 & 14 \\
Jiangxi & 0.08468 & 20 \\
Shandong & 0.54053 & 3 \\
Henan & 0.19773 & 13 \\
Hubei & 0.23070 & 7 \\
Hunan & 0.20433 & 11 \\
Guangdong & 0.76534 & 2 \\
Guangxi & 0.06995 & 23 \\
Hainan & 0.00606 & 30 \\
Chongqing & 0.11440 & 19 \\
Sichuan & 0.21826 & 9 \\
Guizhou & 0.02179 & 27 \\
Yunnan & 0.05431 & 25 \\
Tibet & 0.00000 & 31 \\
Shaanxi & 0.16367 & 15 \\
Gansu & 0.08338 & 21 \\
Qinghai & 0.00972 & 29 \\
Ningxia & 0.01666 & 28 \\
Xinjiang & 0.02440 & 26 \\
\hline & &
\end{tabular}

\section{Conclusion and Suggestion}

An innovation performance appraisal system is being explored for China's hi-tech industry during the process of the industry's continuous development. The essence of the appraisal system is to appraise the performance of the hi-tech industry in each phase by qualitative and quantitative techniques. The exploration of a better appraisal system aims to enrich relevant theories in academic circles and develop and select better performance appraisal system for enterprises in practice so as to improve the innovation activities and performance of China's hi-tech industry with a better appraisal system. Moreover, a better appraisal system will facilitate research on gaps between regions with regard to China's hi-tech industry, strategically contributing to China's balanced and sustainable development.

Based on factor analysis, the innovation performance of China's hi-tech industry is appraised and 
analyzed herein. It is found during the analysis that in the innovation performance appraisal system, the market factor and technology factor influence China's hi-tech industry remarkably while social motive factor isn't given full play to. The following suggestion is made for this situation. In terms of market factor, the government should continue to offer preferential policy and enterprises should advance their capacity for export delivery and new product sales. With regard to technology factor, upholding “independent R\&D”, "go global” and "bring in” strategies, enterprises should improve their capacity for introducing, transforming, digest and absorbing advanced technology from abroad while applying it; with endogenous R\&D as the staple, training of personnel of the hi-tech industry should be strengthened and enterprises should be encouraged to apply for patents in order to improve the capacity for industrial technology innovation in terms of quality. In respect of social motive factor, China's hi-tech industry doesn't make enough use of results of collaboration among enterprises, higher-learning institutions and research institutes, so China should apply the results via scientific research alliance mechanism efficiently and effectively to promote social motives; and the utilization rate of governmental funds and corporate funds should be increased. Improvements based on the 3 factors above will definitely facilitate optimized structure and rapid growth of China's hi-tech industry and at the same time promote balanced and sustainable development of China's hi-tech industry in all the regions.

\section{Acknowledgements}

Fund Project: National Natural Science Foundation of China (71672046) Phased Achievements

\section{References}

[1] National Bureau of Statistics of China and National Development and Reform Commission of China. China’s Technology Statistical Yearbook (2016).

[2] Liu Fengxia. A SPA-Based Study on Appraisal and Incentive of R\&D Personnel of Hi-Tech Enterprises. School of Management, Tianjin University, Tianjin.(2005).

[3] Wang Zong Jun and Xu Xing. A Review of Researches on R\&D Personnel Performance Appraisal. Scientific Research Management (2008): 29(4):84.

[4] Forés B, Camisón C. Does incremental and radical innovation performance depend on different types of knowledge accumulation capabilities and organizational size? [J]. Journal of Business Research, (2016), 69(2):831-848.

[5] Wu J, Wang C, Hong J, et al. Internationalization and innovation performance of emerging market enterprises: The role of host-country institutional development [J]. Journal of World Business, (2016), 51 (2):251-263. 
Appendix A

\begin{tabular}{|c|c|c|c|c|c|c|c|c|c|c|c|c|c|c|c|c|}
\hline $\begin{array}{l}\text { Serial } \\
\text { Number }\end{array}$ & M1 & M2 & M3 & M4 & $\mathrm{T} 1$ & $\mathrm{~T} 2$ & T3 & $\mathrm{T} 4$ & $\mathrm{~T} 5$ & T6 & $\mathrm{T} 7$ & $\mathrm{~T} 8$ & S1 & $\mathrm{S} 2$ & S3 & S4 \\
\hline Beijing & 0.027 & 0.175 & 0.221 & 0.090 & 0.560 & 0.958 & 0.134 & 0.095 & 0.764 & 0.212 & 0.325 & 0.025 & 0.125 & 0.603 & 0.380 & 1.000 \\
\hline Tianjin & 0.132 & 0.168 & 0.280 & 0.083 & 0.167 & 0.266 & 0.136 & 0.074 & 0.212 & 0.178 & 0.381 & 0.244 & 0.108 & 0.190 & 0.239 & 0.091 \\
\hline Hebei & 0.133 & 0.135 & 0.112 & 0.012 & 0.178 & 0.180 & 0.065 & 0.029 & 0.281 & 0.352 & 0.217 & 0.661 & 0.128 & 0.203 & 0.171 & 0.056 \\
\hline Shanxi & 0.009 & 0.094 & 0.059 & 0.004 & 0.131 & 0.103 & 0.041 & 0.027 & 0.182 & 0.244 & 0.116 & 0.299 & 0.060 & 0.147 & 0.105 & 0.026 \\
\hline $\begin{array}{l}\text { Inner } \\
\text { Mongolia }\end{array}$ & 0.013 & 0.047 & 0.053 & 0.000 & 0.068 & 0.073 & 0.016 & 0.010 & 0.099 & 0.249 & 0.050 & 0.077 & 0.041 & 0.070 & 0.073 & 0.018 \\
\hline Liaoning & 0.151 & 0.272 & 0.185 & 0.038 & 0.243 & 0.334 & 0.098 & 0.051 & 0.354 & 0.431 & 0.104 & 0.160 & 0.101 & 0.280 & 0.301 & 0.137 \\
\hline Jilin & 0.044 & 0.028 & 0.133 & 0.001 & 0.128 & 0.087 & 0.025 & 0.013 & 0.207 & 0.050 & 0.018 & 0.019 & 0.033 & 0.143 & 0.061 & 0.060 \\
\hline Heilongjiang & 0.016 & 0.096 & 0.052 & 0.001 & 0.176 & 0.142 & 0.037 & 0.033 & 0.272 & 0.152 & 0.098 & 0.134 & 0.051 & 0.183 & 0.112 & 0.078 \\
\hline Shanghai & 0.116 & 0.419 & 0.479 & 0.370 & 0.389 & 0.561 & 0.237 & 0.171 & 0.474 & 0.255 & 1.000 & 1.000 & 0.230 & 0.395 & 0.448 & 0.301 \\
\hline Jiangsu & 1.000 & 1.000 & 0.836 & 0.722 & 0.916 & 1.000 & 0.711 & 0.272 & 0.794 & 1.000 & 0.590 & 0.457 & 1.000 & 0.909 & 1.000 & 0.241 \\
\hline Zhejiang & 0.104 & 0.485 & 0.573 & 0.096 & 0.647 & 0.575 & 0.522 & 0.167 & 0.489 & 0.468 & 0.349 & 0.369 & 0.929 & 0.641 & 0.613 & 0.100 \\
\hline Anhui & 0.130 & 0.230 & 0.172 & 0.003 & 0.183 & 0.189 & 0.175 & 0.061 & 0.217 & 0.172 & 0.073 & 0.116 & 0.165 & 0.209 & 0.167 & 0.074 \\
\hline Fujian & 0.126 & 0.175 & 0.188 & 0.111 & 0.220 & 0.198 & 0.132 & 0.045 & 0.196 & 0.152 & 0.381 & 0.083 & 0.230 & 0.224 & 0.208 & 0.035 \\
\hline Jiangxi & 0.304 & 0.078 & 0.068 & 0.011 & 0.098 & 0.100 & 0.028 & 0.011 & 0.130 & 0.094 & 0.120 & 0.024 & 0.075 & 0.117 & 0.094 & 0.035 \\
\hline Shandong & 0.185 & 0.703 & 0.765 & 0.116 & 0.551 & 0.783 & 0.374 & 0.152 & 0.639 & 0.622 & 0.409 & 0.561 & 0.476 & 0.615 & 0.845 & 0.123 \\
\hline Henan & 0.123 & 0.200 & 0.149 & 0.004 & 0.292 & 0.245 & 0.135 & 0.053 & 0.345 & 0.282 & 0.099 & 0.107 & 0.285 & 0.320 & 0.242 & 0.065 \\
\hline Hubei & 0.093 & 0.243 & 0.211 & 0.028 & 0.281 & 0.307 & 0.132 & 0.069 & 0.377 & 0.274 & 0.311 & 0.103 & 0.184 & 0.318 & 0.271 & 0.129 \\
\hline Hunan & 0.120 & 0.156 & 0.211 & 0.003 & 0.208 & 0.216 & 0.152 & 0.187 & 0.256 & 0.574 & 0.097 & 0.230 & 0.203 & 0.243 & 0.212 & 0.054 \\
\hline Guangdong & 0.441 & 0.821 & 1.000 & 1.000 & 1.000 & 0.943 & 1.000 & 1.000 & 1.000 & 0.374 & 0.911 & 0.270 & 0.742 & 1.000 & 0.998 & 0.137 \\
\hline Guangxi & 0.045 & 0.052 & 0.086 & 0.007 & 0.095 & 0.072 & 0.026 & 0.017 & 0.133 & 0.205 & 0.006 & 0.019 & 0.073 & 0.114 & 0.063 & 0.030 \\
\hline Hainan & 0.003 & 0.005 & 0.008 & 0.000 & 0.011 & 0.006 & 0.004 & 0.005 & 0.010 & 0.003 & 0.000 & 0.005 & 0.007 & 0.013 & 0.003 & 0.006 \\
\hline Chongqing & 0.034 & 0.115 & 0.230 & 0.004 & 0.104 & 0.115 & 0.113 & 0.045 & 0.136 & 0.114 & 0.231 & 0.073 & 0.109 & 0.129 & 0.106 & 0.042 \\
\hline Sichuan & 0.113 & 0.143 & 0.136 & 0.034 & 0.240 & 0.307 & 0.105 & 0.054 & 0.319 & 0.509 & 0.123 & 0.140 & 0.091 & 0.289 & 0.153 & 0.315 \\
\hline Guizhou & 0.002 & 0.035 & 0.029 & 0.001 & 0.040 & 0.033 & 0.030 & 0.018 & 0.056 & 0.112 & 0.021 & 0.009 & 0.030 & 0.049 & 0.028 & 0.014 \\
\hline Yunnan & 0.000 & 0.034 & 0.021 & 0.001 & 0.062 & 0.050 & 0.017 & 0.017 & 0.085 & 0.093 & 0.089 & 0.032 & 0.048 & 0.081 & 0.034 & 0.035 \\
\hline Tibet & 0.000 & 0.000 & 0.000 & 0.000 & 0.000 & 0.000 & 0.000 & 0.000 & 0.000 & 0.000 & 0.000 & 0.000 & 0.000 & 0.000 & 0.000 & 0.000 \\
\hline Shanxi & 0.516 & 0.114 & 0.082 & 0.005 & 0.210 & 0.252 & 0.057 & 0.033 & 0.320 & 0.171 & 0.056 & 0.037 & 0.079 & 0.218 & 0.108 & 0.276 \\
\hline Gansu & 0.001 & 0.025 & 0.032 & 0.000 & 0.059 & 0.047 & 0.019 & 0.008 & 0.089 & 0.077 & 0.097 & 0.424 & 0.034 & 0.067 & 0.033 & 0.032 \\
\hline Qinghai & 0.002 & 0.004 & 0.001 & 0.000 & 0.010 & 0.010 & 0.002 & 0.001 & 0.014 & 0.008 & 0.011 & 0.029 & 0.007 & 0.014 & 0.009 & 0.004 \\
\hline Ningxia & 0.000 & 0.012 & 0.009 & 0.001 & 0.015 & 0.012 & 0.007 & 0.004 & 0.015 & 0.056 & 0.022 & 0.029 & 0.022 & 0.020 & 0.012 & 0.003 \\
\hline Xinjiang & 0.001 & 0.025 & 0.023 & 0.000 & 0.038 & 0.029 & 0.012 & 0.008 & 0.062 & 0.033 & 0.000 & 0.009 & 0.021 & 0.044 & 0.025 & 0.015 \\
\hline
\end{tabular}

